\title{
Standardized phenology monitoring methods to track plant and animal activity for science and resource management applications
}

\author{
Ellen G. Denny • Katharine L. Gerst • Abraham J. Miller-Rushing • Geraldine L. Tierney • \\ Theresa M. Crimmins - Carolyn A. F. Enquist • Patricia Guertin - Alyssa H. Rosemartin • \\ Mark D. Schwartz • Kathryn A. Thomas • Jake F. Weltzin
}

Received: 27 February 2013 /Revised: 18 December 2013 / Accepted: 5 January 2014 / Published online: 25 January 2014

(C) The Author(s) 2014. This article is published with open access at Springerlink.com

\begin{abstract}
Phenology offers critical insights into the responses of species to climate change; shifts in species' phenologies can result in disruptions to the ecosystem processes and services upon which human livelihood depends. To better detect such shifts, scientists need long-term phenological records covering many taxa and across a broad geographic distribution. To date, phenological observation efforts across the USA have been geographically limited and have used different methods, making comparisons across sites and species difficult. To facilitate coordinated cross-site, cross-species, and geographically extensive phenological monitoring across the nation, the USA National Phenology Network has developed in situ monitoring protocols standardized across taxonomic groups and ecosystem types for terrestrial, freshwater, and marine plant and animal taxa. The protocols include elements
\end{abstract}

Electronic supplementary material The online version of this article (doi:10.1007/s00484-014-0789-5) contains supplementary material, which is available to authorized users.

E. G. Denny $(\bowtie) \cdot$ K. L. Gerst $\cdot$ A. J. Miller-Rushing $\cdot$

T. M. Crimmins - C. A. F. Enquist - P. Guertin - A. H. Rosemartin •

K. A. Thomas $\cdot$ J. F. Weltzin

National Coordinating Office, USA National Phenology Network,

1955 East Sixth Street, Tucson, AZ 85721, USA

e-mail: ellen@usanpn.org

E. G. Denny • K. L. Gerst • T. M. Crimmins • P. Guertin •

A. H. Rosemartin

School of Natural Resources and the Environment,

University of Arizona, Tucson, AZ 85721, USA

\section{A. J. Miller-Rushing}

Schoodic Education and Research Center and Acadia National Park,

National Park Service, Winter Harbor, ME 04693, USA

\section{G. L. Tierney}

SUNY College of Environmental Science and Forestry, Syracuse,

NY 13210, USA that allow enhanced detection and description of phenological responses, including assessment of phenological "status", or the ability to track presence-absence of a particular phenophase, as well as standards for documenting the degree to which phenological activity is expressed in terms of intensity or abundance. Data collected by this method can be integrated with historical phenology data sets, enabling the development of databases for spatial and temporal assessment of changes in status and trends of disparate organisms. To build a common, spatially, and temporally extensive multitaxa phenological data set available for a variety of research and science applications, we encourage scientists, resources managers, and others conducting ecological monitoring or research to consider utilization of these standardized protocols for tracking the seasonal activity of plants and animals.

\section{A. F. Enquist}

The Wildlife Society, Bethesda, MD 20816, USA

M. D. Schwartz

Department of Geography, University of Wisconsin-Milwaukee, Milwaukee, WI 53201, USA

K. A. Thomas

U.S. Geological Survey, Southwest Biological Science Center,

Tucson, AZ, USA

J. F. Weltzin

U.S. Geological Survey, Tucson, AZ, USA 
Keywords Animal $\cdot$ Climate change $\cdot$ Methods . Monitoring $\cdot$ Phenology $\cdot$ Plant $\cdot$ Protocol

\section{Introduction}

Phenology is the study of the seasonally recurrent activity of plants and animals, such as the timing of plant flowering or bird migration, and is central to understanding ecological interactions in the natural and modified systems upon which human society depends. Contemporary climate change has resulted in widespread and ongoing shifts in phenology across many taxa and within varied geographic regions (Parmesan 2006; Cleland et al. 2007; Thackeray et al. 2010). Such shifts in species' phenologies can affect ecosystem processes and functioning. For instance, changes in plant and animal phenology have been linked to shifts in timing of wildfires (Westerling et al. 2006), disease (Grulke 2011), carbon cycling (Keeling et al. 1996; Richardson et al. 2009; Hufkens et al. 2012), species interactions (van Asch and Visser 2007; Burkle et al. 2013), and the distribution and abundance of species (Both et al. 2006; Willis et al. 2008; Chuine 2010). In addition, changes in phenology can result in alterations to agricultural practices (Hu et al. 2005; Wolfe et al. 2005; Schwartz et al. 2006), allergy seasons (Van Vliet et al. 2002; Ziska et al. 2011), and the timing of cultural activities, such as blossom festivals (Aono and Kazui 2008; Chung et al. 2011) and public visitation to national parks (Buckley and Foushee 2012).

Numerous studies examining long-term phenological records from the past 50 to 100 years have demonstrated clear changes in the timing of phenological events in taxa including birds, plants, butterflies, and mammals (Inouye et al. 2000; Peñuelas et al. 2002; Gordo and Sanz 2009; Thackeray et al. 2010; Bartomeus et al. 2011; Ovaskainen et al. 2013). These studies have primarily documented advances in spring plant and animal activity, though changes in summer and autumn events have also been documented (Vitasse et al. 2009; Ibanez et al. 2010; Crimmins et al. 2011; Fridley 2012). Together, these analyses underscore the value of phenology data as an indicator of plant, animal, and ecosystem response to climate change (IPCC 2007).

The majority of studies documenting phenological change have been geographically and taxonomically limited. Further, prior studies have used a wide range of methods, including a variety of categories and definitions for various phenological stages, different criteria for determining the presence of such stages, different sampling methods and frequencies, and different units of observation (e.g., plots, individual plants or animals, etc.), making comparative analyses across studies and species challenging (Root et al. 2003; Parmesan 2007; Thackeray et al. 2010; Tooke and Battey 2010; Menzel et al. 2011; Cook et al. 2012; Diez et al. 2012; Wolkovich et al.
2012). A geographically extensive set of observations, collected using standardized protocols on a regular interval, would offer a much stronger data resource for documenting species' responses to changing climate conditions.

The community of scientists, resource managers, and educators engaged in the USA National Phenology Network (USA-NPN), which was established in 2007, recognized an opportunity for better coordination in phenology data collection (Schwartz et al. 2012b). To this end, members of this group developed a standardized and conceptually integrated method for observing phenology of both plants and animals that can be implemented across polar, temperate, tropical, and water-limited ecosystems. As outlined below, this method includes several elements to enhance the detection and description of phenological responses beyond what is possible with some other methods commonly used in temperate regions in the past. By encouraging those initiating new observation efforts to follow these protocols - and existing observation efforts to develop crosswalks or adopt aspects of the protocols where appropriate - we hope to build a large, spatially and temporally extensive, freely available, phenological data set based on a common sampling method.

Here, we present the general monitoring approach and specific phenophases developed by scientists working as part of the USA-NPN. These protocols are designed for in situ observations of plant and animal phenology across terrestrial, freshwater, and marine ecological systems. We define the term phenophase as an observable stage or phase in the annual life cycle of a plant or animal that can be characterized by a start and an end point. Phenophases typically have a duration of a few days or weeks. Examples of phenophases include the period over which newly emerging leaves are visible or the period during which frogs are calling.

\section{Attributes and advantages of monitoring methods}

These standardized protocols are designed to quantify the onset, duration, and intensity of phenological stages of plants and animals to understand how life cycles track environmental variation. The protocols can be tailored to any sampling density or frequency depending on available resources and the science or management question under investigation, and enable integrated monitoring of both plants and animals to address questions related to both populations and communities. The phenophase categories associated with particular life forms and functional types are summarized in Tables 1, 2, 3, 4, and corresponding phenophase definitions are outlined in detail in Online Resource 1. The monitoring method is characterized by several elements that allow for enhanced detection and description of phenological responses through time including (1) repeated assessment of phenophase "status" to provide explicit information on presence as well as absence of 


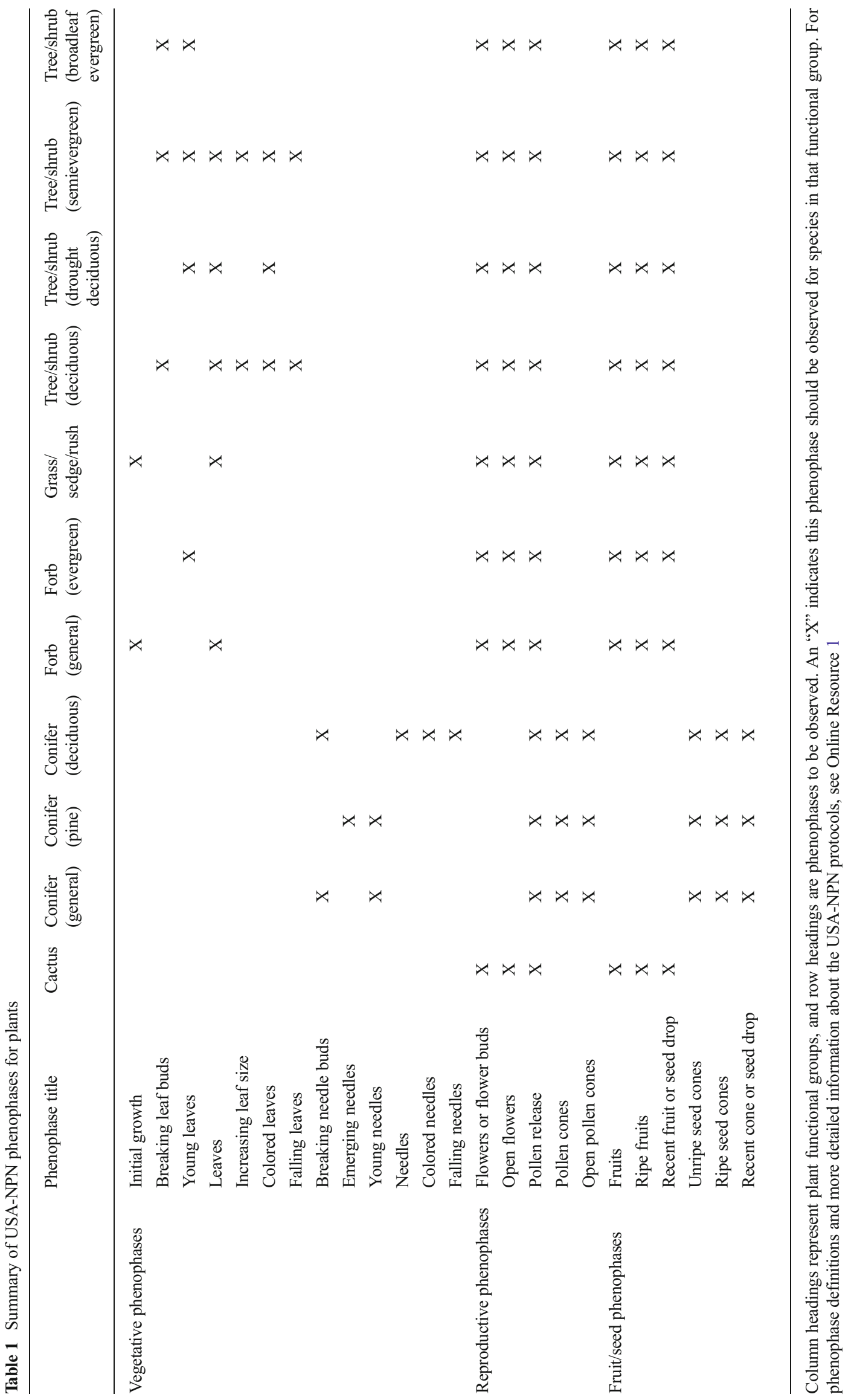


Table 2 Summary of USA-NPN phenophases for insects

\begin{tabular}{|c|c|c|c|c|c|c|c|c|}
\hline Phenophase title & Mayfly & Dragonfly/damselfly & Grasshopper & Stonefly & Tiger beetle & Butterfly & Moth & Bee \\
\hline Active adults & $\mathrm{X}$ & $\mathrm{X}$ & $\mathrm{X}$ & $\mathrm{X}$ & $\mathrm{X}$ & $\mathrm{X}$ & $\mathrm{X}$ & $\mathrm{X}$ \\
\hline Adults feeding & & $\mathrm{X}$ & $\mathrm{X}$ & & $\mathrm{X}$ & & & \\
\hline Flower visitation & & & & & & $\mathrm{X}$ & & $\mathrm{X}$ \\
\hline Migrating adults & & $\mathrm{X}$ & & & & $\mathrm{X}$ & & \\
\hline Mating & $\mathrm{X}$ & $\mathrm{X}$ & $\mathrm{X}$ & $\mathrm{X}$ & $\mathrm{X}$ & $\mathrm{X}$ & $\mathrm{X}$ & $\mathrm{X}$ \\
\hline Egg laying & & $\mathrm{X}$ & & & & & & \\
\hline Active subadults & $\mathrm{X}$ & & & & & & & \\
\hline Active caterpillars & & & & & & $\mathrm{X}$ & $\mathrm{X}$ & \\
\hline Caterpillars in tent & & & & & & & $\mathrm{X}$ & \\
\hline Caterpillars feeding & & & & & & $\mathrm{X}$ & $\mathrm{X}$ & \\
\hline Dead caterpillars & & & & & & $\mathrm{X}$ & $\mathrm{X}$ & \\
\hline Active nymphs & & & $\mathrm{X}$ & & & & & \\
\hline Nymphs feeding & & & $\mathrm{X}$ & & & & & \\
\hline Dead nymphs & & & $\mathrm{X}$ & & & & & \\
\hline Dead adults & $\mathrm{X}$ & $\mathrm{X}$ & $\mathrm{X}$ & $\mathrm{X}$ & $\mathrm{X}$ & $\mathrm{X}$ & $\mathrm{X}$ & $\mathrm{X}$ \\
\hline Individuals at a feeding station & & & & & & $\mathrm{X}$ & $\mathrm{X}$ & \\
\hline Individuals at a light & & & & & $\mathrm{X}$ & & $\mathrm{X}$ & \\
\hline Individuals in a net & $\mathrm{X}$ & $\mathrm{X}$ & $\mathrm{X}$ & $\mathrm{X}$ & $\mathrm{X}$ & $\mathrm{X}$ & $\mathrm{X}$ & \\
\hline
\end{tabular}

Column headings represent insect guilds, and row headings are phenophases to be observed. An " $\mathrm{X}$ " indicates this phenophase should be observed for species in that guild. Note that phenophases for advanced insect observers are not included here, and protocols have yet to be developed for several important insect taxa. For phenophase definitions and more detailed information about the USA-NPN protocols, see Online Resource 1

a phenophase, (2) intensity or abundance of phenophases, (3) independent tracking of different and potentially overlapping phenophases, and (4) monitoring of multiple individuals within a population.

The first key element that defines the monitoring method is the periodic assessment of the "status" of the phenophase for an organism, rather than simply recording the date of an "event" (Fig. 1). Historically, many individuals and phenological monitoring programs have recorded the timing of phenological events - that is, precisely defined points in the annual life cycles of plants or animals (e.g., Sparks and Carey 1995; Bradley et al. 1999; Fitter and Fitter 2002; Miller-Rushing and Primack 2008). Examples of phenological events include first leaf and first flower of plant individuals or species, or first arrival and first departure of migratory animal species. Event data have been instrumental in documenting changes in spring leaf and flower onset in many studies, as well as changes in migration timing and species interactions (e.g., Bradley et al. 1999; Inouye 2008; McKinney et al. 2012). Data collected via a status monitoring approach can offer even more information and further insight into species' phenology than can be gleaned from event monitoring. For instance, event-based monitoring generally misses repeat events (e.g., a second flush of leaves after a killing frost or a second round of flowering within a season (Crimmins et al. 2013), Fig. 1b). As such, event-based monitoring is impractical in tropical or subtropical systems where the beginning (or end) of a season or a phenophase is often difficult to define. For this reason, monitoring methods in tropical regions have long employed continuous assessment of phenophases (Morellato et al. 2010). Moreover, event-based monitoring (e.g., first frog call of the season or first hummingbird at a feeder) does not necessarily reflect the population-level behaviors of interest to resource managers (Miller-Rushing et al. 2008a, b).

Instead of recording the date of phenological events directly, status monitoring involves evaluating phenophase status (e.g., the presence or absence of leaves, flowers, or fruits for plants, and mating, feeding, or movement for animals) during a series of repeated observations over the course of a season (e.g., Frankie et al. 1974; Inouye and McGuire 1991; Borchert 1994; Sparks et al. 2005; Morellato et al. 2010; Crimmins et al. 2011) (Fig. 1). Observations are expressed as the question, "Do you see [phenophase]?" to which the observer answers "yes", "no", or "uncertain" for the presence of each phenophase (Fig. 2). Depending on frequency of observation, this approach provides explicit information on presence, absence, and duration of phenophases, as well as any withinseason gaps in the presence of a phenophase resulting from periodic or repeated activity (e.g., flushes of leaves or flowers, or pulses of migratory animals) (Fig. 1b). This approach also enables conceptual and actual integration of the observation of sessile (e.g., plants) and mobile (e.g., birds) organisms at the 
Table 3 Summary of USA-NPN phenophases for fish, amphibians, and reptiles

\begin{tabular}{|c|c|c|c|c|c|c|c|c|c|}
\hline Phenophase title & Fish (saltwater) & $\begin{array}{l}\text { Fish } \\
\text { (anadromous) }\end{array}$ & $\begin{array}{l}\text { Fish } \\
\text { (freshwater) }\end{array}$ & Eel & Salamander & Toad/frog & Alligator & Turtle & Lizard/snake \\
\hline Individuals on land & & & & & & & $\mathrm{X}$ & $\mathrm{X}$ & $\mathrm{X}$ \\
\hline Adults on land & & & & & $\mathrm{X}$ & $\mathrm{X}$ & & & \\
\hline Individuals in water & & & & & & & $\mathrm{X}$ & $\mathrm{X}$ & $\mathrm{X}$ \\
\hline Adults in water & & & & & $\mathrm{X}$ & $\mathrm{X}$ & & & \\
\hline Adults in freshwater & & $\mathrm{X}$ & $\mathrm{X}$ & $\mathrm{X}$ & & & & & \\
\hline Adults in saltwater & $\mathrm{X}$ & $\mathrm{X}$ & & $\mathrm{X}$ & & & & & \\
\hline Feeding & & & & & & & $\mathrm{X}$ & $\mathrm{X}$ & $\mathrm{X}$ \\
\hline Adults feeding & $\mathrm{X}$ & $\mathrm{X}$ & $\mathrm{X}$ & $\mathrm{X}$ & $\mathrm{X}$ & $\mathrm{X}$ & & & \\
\hline Adults migrating upstream & & $X$ & & & & & & & \\
\hline Adults migrating downstream & & $\mathrm{X}$ & $\mathrm{X}$ & $\mathrm{X}$ & & & & & \\
\hline Juveniles in saltwater & $\mathrm{X}$ & & & & & & & & \\
\hline Juveniles moving upstream & & & & $X$ & & & & & \\
\hline Vocalizing & & & & & & $\mathrm{X}$ & & & \\
\hline Adults vocalizing & & & & & & & $\mathrm{X}$ & & \\
\hline Mating & & & & & $\mathrm{X}$ & $X$ & & & \\
\hline Nesting & & & & & & & & $\mathrm{X}$ & \\
\hline Fresh eggs & & & & & $X$ & $\mathrm{X}$ & & & \\
\hline Young individuals & & & & & & & $\mathrm{X}$ & $\mathrm{X}$ & $\mathrm{X}$ \\
\hline Dead individuals & & & & & & & $\mathrm{X}$ & $\mathrm{X}$ & $\mathrm{X}$ \\
\hline Dead adults & & & & & $\mathrm{X}$ & $\mathrm{X}$ & & & \\
\hline Dead or dying adults & $\mathrm{X}$ & $\mathrm{X}$ & $\mathrm{X}$ & $\mathrm{X}$ & & & & & \\
\hline Individuals on a hook & $\mathrm{X}$ & $\mathrm{X}$ & $\mathrm{X}$ & $\mathrm{X}$ & & & & & \\
\hline Individuals in a net & $X$ & $X$ & $\mathrm{X}$ & $\mathrm{X}$ & & & & & \\
\hline
\end{tabular}

Column headings represent animal guilds, and row headings are phenophases to be observed. An " $\mathrm{X}$ " indicates this phenophase should be observed for species in that guild. Note that phenophases for advanced animal observers are not included here. For phenophase definitions and more detailed information about the USA-NPN protocols, see Online Resource 1

same location, making it possible, for example, to explicitly record whether pollinators are present while flowers are open or whether leaves are present at the time caterpillars hatch. In sum, this integrated multi-taxa approach creates an integrated framework for tracking phenology of both plants and animals at the level of either populations or communities.

Phenophase status monitoring also allows determination of phenological event dates from the resulting data, depending on the application or information needs of the user. For example, the date of the first report of presence after a report of absence for open flowers can be interpreted to reflect the event date of "first flower", though the user can define custom criteria for defining events. Alternatively, event-based data can be mapped onto status-based data; for example, historical event-based observations of lilacs were integrated into the status-based database of the USA-NPN, extending the spatial and temporal range of the USA-NPN database (Schwartz et al. 2012a).

In situations where observations are impossible to make everyday (e.g., remote locations), status-based monitoring provides a mechanism to quantify the uncertainty in the event date by capturing the frequency of observation (e.g., the number of days that passed between the last report of absence and the first report of presence). Status monitoring enables observers to record data each time they make an observation (i.e., "yes," "no," or "uncertain"), which can be more active and engaging than event-based monitoring. Finally, with status monitoring, even a single observation of phenophase presence or absence is potentially useful as it can be combined with observations of other observers.

A second element that characterizes the monitoring method is the inclusion of intensity or abundance measures associated with the presence of a particular phenophase (Figs. 1 and 2). In addition to documenting the presence or absence of a phenophase, observers also may record the intensity or abundance of each phenophase (e.g., number of flowers present, percentage of flowers open, number of robins feeding, etc.). For example, rather than simply collecting data on the presence of open flowers on a given plant, these protocols allow an observer to also document the total number of flowers and the proportion of flowers that are open on a given day. These data could be used to identify periods of low flower abundance that 
Table 4 Summary of USA-NPN phenophases for birds and mammals

\begin{tabular}{|c|c|c|c|c|c|c|c|c|}
\hline Phenophase title & $\begin{array}{l}\text { Bird } \\
\text { (general) }\end{array}$ & Shorebird & Hummingbird & Songbird & $\begin{array}{l}\text { Mammal } \\
\text { (general) }\end{array}$ & Pinniped & Squirrel/chipmunk & Deer/sheep \\
\hline Active individuals & $\mathrm{X}$ & $\mathrm{X}$ & $\mathrm{X}$ & $\mathrm{X}$ & $\mathrm{X}$ & & $\mathrm{X}$ & $\mathrm{X}$ \\
\hline Individuals on land & & & & & & $\mathrm{X}$ & & \\
\hline Individuals in water & & & & & & $\mathrm{X}$ & & \\
\hline Feeding & $\mathrm{X}$ & $\mathrm{X}$ & $\mathrm{X}$ & $\mathrm{X}$ & $\mathrm{X}$ & $\mathrm{X}$ & $\mathrm{X}$ & $\mathrm{X}$ \\
\hline Fruit/seed consumption & $X$ & & & $\mathrm{X}$ & & & $\mathrm{X}$ & \\
\hline Insect consumption & $\mathrm{X}$ & & $\mathrm{X}$ & $\mathrm{X}$ & & & & \\
\hline Flower visitation & & & $\mathrm{X}$ & $\mathrm{X}$ & & & & \\
\hline Nut gathering & $X$ & & & & & & $\mathrm{X}$ & \\
\hline Calls or song & $\mathrm{X}$ & $X$ & $\mathrm{X}$ & $\mathrm{X}$ & & & & \\
\hline Singing males & & & $\mathrm{X}$ & $\mathrm{X}$ & & & & \\
\hline Males vocalizing & & & & & & & & $X$ \\
\hline Male combat & & & & & & $\mathrm{X}$ & & $\mathrm{X}$ \\
\hline Mating & $\mathrm{X}$ & $\mathrm{X}$ & $\mathrm{X}$ & $\mathrm{X}$ & $\mathrm{X}$ & $\mathrm{X}$ & & $\mathrm{X}$ \\
\hline Nest building & $\mathrm{X}$ & & $\mathrm{X}$ & $\mathrm{X}$ & & & & \\
\hline Young individuals & & & & & $\mathrm{X}$ & $\mathrm{X}$ & $\mathrm{X}$ & $\mathrm{X}$ \\
\hline Summer coat & & & & & $\mathrm{X}$ & & & \\
\hline Winter coat & & & & & $\mathrm{X}$ & & & \\
\hline Dead individuals & $\mathrm{X}$ & $\mathrm{X}$ & $\mathrm{X}$ & $\mathrm{X}$ & $\mathrm{X}$ & $\mathrm{X}$ & $\mathrm{X}$ & $\mathrm{X}$ \\
\hline Individuals at a feeding station & $\mathrm{X}$ & & $\mathrm{X}$ & $\mathrm{X}$ & & & & \\
\hline
\end{tabular}

Column headings represent animal guilds, and row headings are phenophases to be observed. An " $\mathrm{X}$ " indicates this phenophase should be observed for species in that guild. Note that phenophases for advanced animal observers are not included here. For phenophase definitions and more detailed information about the USA-NPN protocols, see Online Resource 1

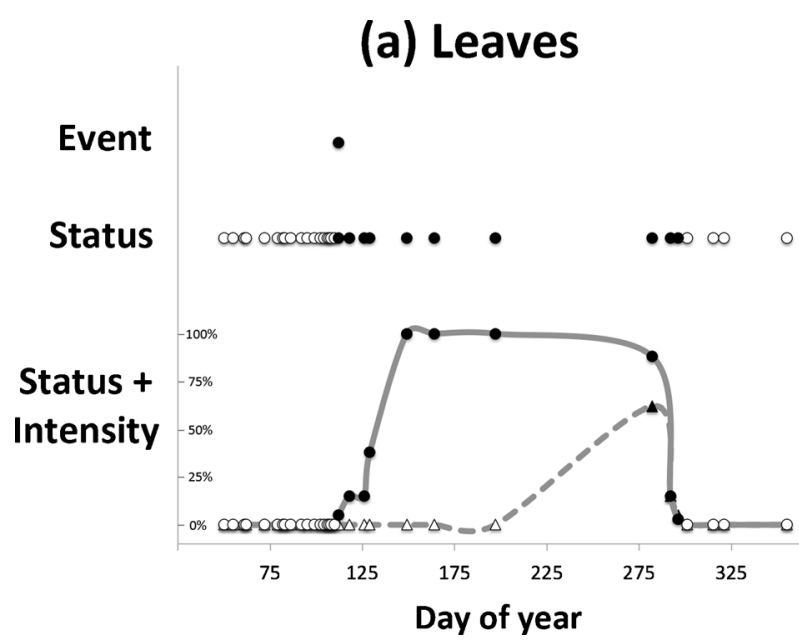

Fig. 1 Visual comparison of data collected by monitoring phenological events, phenophase status, and phenophase status plus intensity. Event monitoring captures onset of a given phenophase, whereas status monitoring captures onset and duration. Status monitoring with intensity (or abundance) captures onset, duration, and magnitude of a phenophase. Examples are derived from 2012 data submitted in Natureś Notebook for (a) sugar maple (Acer saccharum) leafing for one individual plant in Maine, and (b) forsythia flowering (Forsythia sp.) for one individual plant in Massachusetts. Each point represents one observation; black points indicate presence of the phenophase while white points indicate absence. (a) illustrates the date on which the first leaf appears (event), the period during which leaves are present (status), and the period and rate at which

\section{(b) Open flowers}

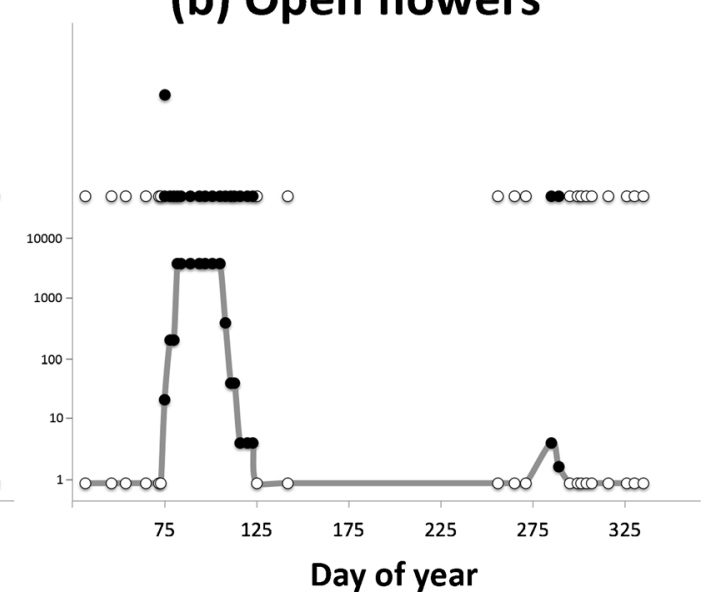

the canopy fills from 0 to $100 \%$ capacity and then, empties back to 0 with leaf fall (status + intensity, circles and solid line) using estimates of canopy fullness. Also illustrated is the period and rate at which the canopy fills and empties of autumn colored leaves (status+intensity, triangles and dashed line). (b) illustrates the date on which the first open flower appears (event), the periods during which open flowers are present on the plant (status), and an estimate of the number of open flowers on the plant over the periods in which they are present (status + intensity). In both examples, the event point is calculated as the first date of the year where the phenophase was reported as present. Note that in (b) there are two distinct periods of flowering, the second of which would not have been captured using event monitoring alone 


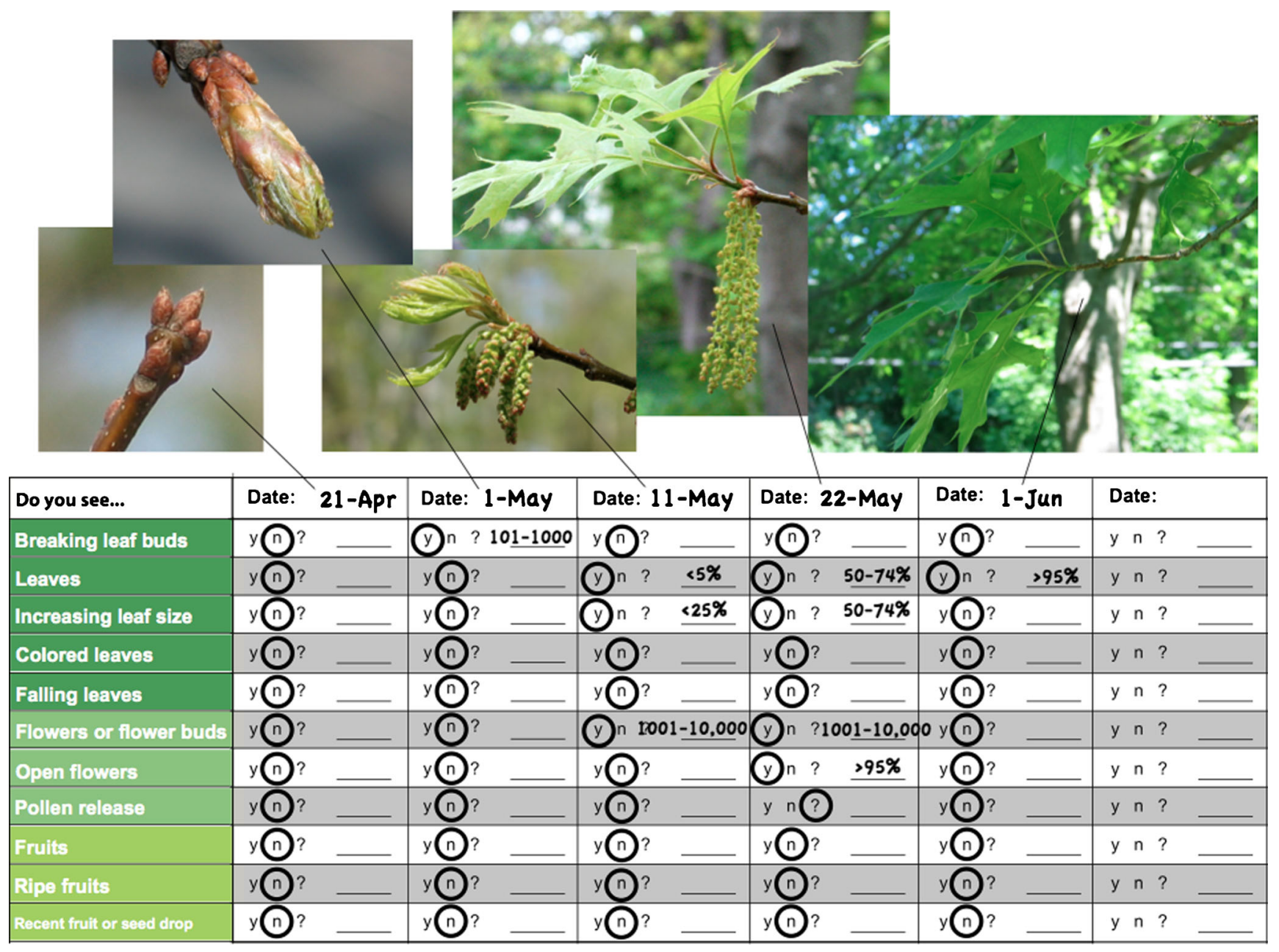

Fig. 2 An illustration of how an observer would make and record repeated observations for a single individual plant (in this case a black oak tree, Quercus velutina) over a period of time. Circles around the "y's" (yes) and "n's" (no) indicate the presence or absence of the phenophases (far left column) on the tree for each date. When a phenophase is present, an estimate of intensity is included (see Online Resource 1 for intensity

may be important for plant reproduction, for pollinators, or for other flower-dependent species (Miller-Rushing and Inouye 2009; Aldridge et al. 2011). For animal species, recording abundance facilitates detection of important population trends, such as declines or increases within and across years, and the timing of pulses of migration or breeding that might be particularly important for resource managers. Coupled with phenophase status monitoring, these intensity and abundance measures allow researchers to better characterize and model phenological patterns in time and space using metrics such as duration, magnitude, mean and skew (e.g., Thomson 1980). They also facilitate assessments of potential interactions among species (Durant et al. 2005; Miller-Rushing et al. 2010).

The third feature that characterizes the monitoring method is the independent tracking of unique phenophases on an individual plant or animal species regardless of whether or measures). In this example, the phenological event of "first leaf" (Meier 2001) would have occurred between May 1st and May 11th, the dates of the last reported "no" and the first reported "yes" for the "Leaves" phenophase. Although there are approximately 10 days between each observation in this example, more frequent observation will be desired in many cases

not the phenophases are occurring at the same time. For example, an observer documenting the phenology of a deciduous tree would evaluate several leaf phenophases independently of each other during each observation, including the presence and percentage of any leaves (green or colored) and the presence and percentage specifically of colored (nongreen) leaves. Thus, an observer may document the presence of both green and colored leaves on one visit, and the presence of colored leaves and absence of green leaves on a subsequent visit (Fig. 1a). This feature allows for greater flexibility in understanding the complex relationships between climate, environmental cues, and phenology as evaluation of separate phenophase responses permits researchers to tease apart interactions among these variables. For instance, researchers can now evaluate the effect of drought on leaf color change and leaf drop independently. Likewise, a researcher can tease apart the effects of temperature on flower production and the 
opening of flowers. This creates a richer, more complex data set than other methods that might be designed to determine the single dominant phenophase or phenological condition of an individual organism at a given point in time (e.g., Richardson et al. 2006).

A final defining feature of the monitoring method is that the phenology of individual plants is tracked independently, and multiple individuals of the same species can be observed at the same location. This allows researchers to quantify phenological variation within a population as well as across species and geographic regions. A key gap in our understanding of how species will respond to climate change is predicting the extent to which organisms will be able to keep pace with their changing environment (Gienapp et al. 2008; Hoffmann and Sgrò 2011). Characterizing the range of inter- and intraspecific phenological responses to temporal and spatial variation in climate will allow for better understanding of species capacity to respond to shifting abiotic conditions and improved attribution of observed phenological shifts to evolutionary processes vs. adaptive plastic responses. In particular, these data can be used to complement and inform genetic studies and common garden experiments that aim to elucidate mechanisms of adaptation to a changing climate (e.g., Franks et al. 2007).

\section{Development and implementation of monitoring methods}

The standardized protocols presented herein were developed with an input from a large and diverse community of researchers and resource managers with expertise in phenology, ecology, or climate change science, and/or practical experience in the collection and analysis of human-observed field data of select taxonomic groups. Usability feedback from educators and volunteer observers informed subsequent revisions to the protocols. See www.usanpn.org/plant-animalcredits for a list of all contributors to the protocol development. Objectives used to guide the development of the monitoring approach and phenophase definitions include applicability across a wide range of biomes and species, usability for observers with varying levels of skill (professional scientists and resource managers as well as volunteer observers), and utility for a number of anticipated scientific end-uses of the resulting data, such as detection of changes in the start of spring or autumn leaf color, prediction of allergy seasons, validation of remotely sensed land products, and evaluation and prediction of species range shifts or mismatches in the phenology of species interactions. In addition, the protocols were designed to be compatible with other historical phenology sampling methods, including the European $\mathrm{BBCH}$ scale developed for tracking phenology in agricultural systems and now used broadly in monitoring natural systems across Europe (Meier 2001; Koch et al.
2007), as well as existing volunteer-based phenology monitoring programs such as eBird and FrogWatch USA (Schwartz et al. 2013).

These standardized protocols can be used by any program monitoring phenology. As a case example, these protocols are employed in the USA-NPN's phenology observation program, Nature's Notebook (www.nn.usanpn.org), which engages both professionals and volunteers in observing and recording plant and animal activity across the nation (Schwartz et al. 2012a, b). The resulting data, housed in the USA-NPN's National Phenology Database, are freely available for download, visualization, exploration, and analysis (http://www.usanpn.org/data) (Rosemartin et al. 2013). Because data were collected in Natures's Notebook during development of these standardized protocols, documentation of modifications is provided for data end-users (www.usanpn. org/results/nndocumentation). Several national level organizations and agencies in the USA are using these protocols for phenology observation at pilot sites and/or are in the process of officially adopting them in their standard operating procedures (Tierney et al. 2013; Haggerty et al. 2013) They are also in use by many regional, state, and local partner organizations (e.g., cooperative extension programs, schools, and conservation organizations).

\section{Conclusion}

As the field of phenology expands and its importance in ecology, evolution, and resource management is better defined, the need for high quality standardized observation methods is becoming increasingly clear. The standardized protocols described here provide an approach to enhance detection and description of phenological responses and facilitate greater integration of phenological data collection efforts across the globe. Researchers are using the data generated from these protocols to address a number of science questions on regional to continental scales (Schwartz et al. 2012b; Euskirchen et al. 2013; Jeong et al. 2013; Liang and Schwartz 2013). Integrated with other types of data relevant to plant and animal phenology (e.g., climate data, satellite and ground-based remote sensing products, physiological and demographic measurements, data on human behaviors, and health issues), data generated with these protocols will expand our ability to carry out collaborative and comparative studies, provide new insights into the causes and consequences of changes in phenology on a broad range of spatial and temporal scales, and significantly advance our understanding of ecosystem functioning and the impacts of climate change. In sum, we encourage those working within and across the fields of ecology, animal behavior, resource management, ecosystem science, and climatology to incorporate phenological 
monitoring into long-term studies using these status-based phenology protocols.

\section{Acknowledgments}

EGD, AJM, GLT, and JFW contributed to the theoretical framework for the monitoring approach and conceptual development of plant and animal protocols. Additionally, KLG, MDS, TMC, PG, and KAT contributed to the conceptual development of plant protocols, and AHR contributed to the conceptual development of animal protocols. KLG drafted the manuscript text. AJM, GLT, TMC, CAFE, AHR, MDS, KAT, and JFW reviewed, and EGD, TMC, and KLG revised the manuscript. Several anonymous reviewers provided valuable comments that significantly improved the manuscript.

Many individuals contributed to the development and review of these phenology protocols over the last 6 years. These individuals are listed online at www.usanpn.org/plant-animalcredits. The USA-NPN gratefully acknowledges the following sponsoring organizations: The US Geological Survey, University of Arizona, University of Wisconsin-Milwaukee, The Wildlife Society, US National Park Service, National Oceanic and Atmospheric Administration, National Aeronautics and Space Administration, National Science Foundation (Research Coordination Network grant, IOS0639794), Oak Ridge National Laboratory, and US Fish and Wildlife Service. We are also grateful to the Northeastern States Research Cooperative (through funding made available by the USDA Forest Service) and Microsoft Research for funding the lead author during the initial years of protocol development. Data for Fig. 1 were provided by two of the many participants who contribute to Natures Notebook.

Any use of trade, product, or firm names is for descriptive purposes only and does not imply endorsement by the US Government.

Open Access This article is distributed under the terms of the Creative Commons Attribution License which permits any use, distribution, and reproduction in any medium, provided the original author(s) and the source are credited.

\section{References}

Aldridge G, Inouye DW, Forrest JRK, Barr WA, Miller-Rushing AJ (2011) Emergence of a mid-season period of low floral resources in a montane meadow ecosystem associated with climate change. $\mathrm{J}$ Ecol 99(4):905-913. doi:10.1111/j.1365-2745.2011.01826.x

Aono Y, Kazui K (2008) Phenological data series of cherry tree flowering in Kyoto, Japan, and its application to reconstruction of springtime temperatures since the 9th century. Int J Climatol 28(7):905-914. doi: $10.1002 /$ joc. 1594
Bartomeus I, Ascher JS, Wagner D, Danforth BN, Colla S, Kornbluth S, Winfree R (2011) Climate-associated phenological advances in bee pollinators and bee-pollinated plants. Proc Natl Acad Sci U S A 108(51):20645-20649. doi:10.1073/pnas.1115559108

Borchert R (1994) Soil and stem water storage determine phenology and distribution of tropical dry forest trees. Ecology 75:1437-1449

Both C, Bouwhuis S, Lessells CM, Visser ME (2006) Climate change and population declines in a long-distance migratory bird. Nature 441(7089):81-83. doi:10.1038/nature04539

Bradley NL, Leopold AC, Ross J, Huffaker W (1999) Phenological changes reflect climate change in Wisconsin. Proc Natl Acad Sci U S A 96(17):9701-9704. doi:10.1073/pnas.96.17.9701

Buckley L, Foushee M (2012) Footprints of climate change in US national park visitation. Int J Biometeorol 56(6):1173-1177. doi: 10.1007/s00484-011-0508-4

Burkle LA, Marlin JC, Knight TM (2013) Plant-pollinator interactions over 120 years: loss of species, co-occurrence, and function. Science 339(6127):1611-1615. doi:10.1126/science. 1232728

Chuine I (2010) Why does phenology drive species distribution? Philos Trans R Soc B Biol Sci 365(1555):3149-3160. doi:10.1098/rstb. 2010.0142

Chung U, Mack L, Yun JI, Kim SH (2011) Predicting the timing of cherry blossoms in Washington, DC and Mid-Atlantic states in response to climate change. PloS ONE 6(11), doi:10.1371/journal.pone. 0027439

Cleland EE, Chuine I, Menzel A, Mooney HA, Schwartz MD (2007) Shifting plant phenology in response to global change. Trends Ecol Evol 22(7):357-365. doi:10.1016/j.tree.2007.04.003

Cook BI, Wolkovich EM, Parmesan C (2012) Divergent responses to spring and winter warming drive community level flowering trends. Proc Natl Acad Sci U S A 109(23):9000-9005. doi:10.1073/pnas. 1118364109

Crimmins TM, Crimmins MA, Bertelsen CD (2011) Onset of summer flowering in a 'Sky Island' is driven by monsoon moisture. New Phytol 191(2):468-479. doi:10.1111/j.1469-8137.2011.03705.x

Crimmins TM, Crimmins MA, Bertelsen CD (2013) Spring and summer patterns in flowering onset, duration, and constancy across a waterlimited gradient. Am J Bot 100(6):1137-1147. doi:10.3732/ajb. 1200633

Diez JM, Ibanez I, Miller-Rushing AJ, Mazer SJ, Crimmins TM, Crimmins MA, Bertelsen CD, Inouye DW (2012) Forecasting phenology: from species variability to community patterns. Ecol Lett 15(6):545-553. doi:10.1111/j.1461-0248.2012.01765.x

Durant JM, Hjermann DO, Anker-Nilssen T, Beaugrand G, Mysterud A, Pettorelli N, Stenseth NC (2005) Timing and abundance as key mechanisms affecting trophic interactions in variable environments. Ecol Lett 8(9):952-958. doi:10.1111/j.1461-0248.2005.00798.x

Euskirchen ES, Carman TB, McGuire AD (2013) Changes in the structure and function of northern Alaskan ecosystems when considering variable leaf-out times across groupings of species in a dynamic vegetation model. Glob Chang Biol In Press

Fitter AH, Fitter RSR (2002) Rapid changes in flowering time in British plants. Science 296(5573):1689-1691. doi:10.1126/science. 1071617

Frankie GW, Baker HG, Opler PA (1974) Comparative phenological studies of trees in tropical wet and dry forests in lowlands of Costa Rica. J Ecol 62:881-919

Franks SJ, Sim S, Weis AE (2007) Rapid evolution of flowering time by an annual plant in response to a climate fluctuation. Proc Natl Acad Sci 104(4):1278-1282. doi:10.1073/pnas.0608379104

Fridley JD (2012) Extended leaf phenology and the autumn niche in deciduous forest invasions. Nature 485(7398):359-362. doi:10. 1038/nature11056

Gienapp P, Teplitsky C, Alho J, Mills J, Merilä J (2008) Climate change and evolution: disentangling environmental and genetic responses. Mol Ecol 17(1):167-178 
Gordo O, Sanz JJ (2009) Long-term temporal changes of plant phenology in the Western Mediterranean. Glob Chang Biol 15(8):1930-1948. doi:10.1111/j.1365-2486.2009.01851.x

Grulke NE (2011) The nexus of host and pathogen phenology: understanding the disease triangle with climate change. New Phytol 189(1):8-11. doi:10.1111/j.1469-8137.2010.03568.x

Haggerty BP, Matthews ER, Gerst KL, Evenden AG, Mazer SJ (2013) The California Phenology Project: tracking plant responses to climate change. Madroño 60(1):1-3. doi:10.3120/0024-9637-60.1.1

Hoffmann A, Sgrò C (2011) Climate change and evolutionary adaptation. Nature 470:479-485. doi:10.1038/nature09670

$\mathrm{Hu}$ Q, Weiss A, Feng S, Baenziger PS (2005) Earlier winter wheat heading dates and warmer spring in the US Great Plains. Agr Forest Meteorol 135(1-4):284-290. doi:10.1016/j.agrformet.2006. 01.001

Hufkens K, Friedl M, Sonnentag O, Braswell BH, Milliman T, Richardson AD (2012) Linking near-surface and satellite remote sensing measurements of deciduous broadleaf forest phenology. Remote Sens Environ 117:307-321. doi:10.1016/j.rse.2011.10.006

Ibanez I, Primack RB, Miller-Rushing AJ, Ellwood E, Higuchi H, Lee SD, Kobori H, Silander JA (2010) Forecasting phenology under global warming. Philos Trans R Soc B Biol Sci 365(1555):32473260. doi:10.1098/rstb.2010.0120

Inouye DW (2008) Effects of climate change on phenology, frost damage, and floral abundance of montane wildflowers. Ecology 89(2):353362. doi:10.1890/06-2128.1

Inouye DW, McGuire AD (1991) Effects of snowpack on timing and abundance of flowering in Delphinium nelsonii (Ranunculaceae): implications for climate change. Am J Bot 78(7):997-1001

Inouye DW, Barr B, Armitage KB, Inouye BD (2000) Climate change is affecting altitudinal migrants and hibernating species. Proc Natl Acad Sci U S A 97(4):1630-1633. doi:10.1073/pnas.97.4.1630

IPCC (2007) Climate change 2007: synthesis report. Contributions of Working Groups I, II, and III to the Fourth Assessment Report of the Intergovernmental Panel on Climate Change. IPCC, Geneva, Switzerland

Jeong S-J, Medvigy D, Shevliakova E, Malyshev S (2013) Predicting changes in temperate forest budburst using continental-scale observations and models. Geophys Res Lett 40(2):359-364. doi:10.1029/ 2012G1054431

Keeling CD, Chin JFS, Whorf TP (1996) Increased activity of northern vegetation inferred from atmospheric $\mathrm{CO} 2$ measurements. Nature 382(6587):146-149. doi:10.1038/382146a0

Koch E, Bruns E, Chmielewski FM, Defila C, Lipa W, Menzel A (2007) Guidelines for plant phenological observations. World Climate Data and Monitoring Programme

Liang L, Schwartz M (2013) Testing a growth efficiency hypothesis with continental-scale phenological variations of common and cloned plants. Int J Biometeorol In Press.

McKinney AM, CaraDonna PJ, Inouye DW, Barr B, Bertelsen CD, Waser NM (2012) Asynchronous changes in phenology of migrating Broad-tailed Hummingbirds and their early-season nectar resources. Ecology 93(9):1987-1993

Meier U (2001) Growth stages of mono-and dicotyledonous plants. BBCH Monograph. Federal Biological Research Centre for Agriculture and Forestry, Germany

Menzel A, Seifert H, Estrella N (2011) Effects of recent warm and cold spells on European plant phenology. Int J Biometeorol 55(6):921932. doi:10.1007/s00484-011-0466-x

Miller-Rushing AJ, Inouye DW (2009) Variation in the impact of climate change on flowering phenology and abundance: an examination of two pairs of closely related wildflower species. Am J Bot 96(10): 1821-1829. doi:10.3732/ajb.0800411

Miller-Rushing AJ, Primack RB (2008) Global warming and flowering times in Thoreau's concord: a community perspective. Ecology 89(2):332-341. doi:10.1890/07-0068.1
Miller-Rushing AJ, Inouye DW, Primack RB (2008a) How well do first flowering dates measure plant responses to climate change? The effects of population size and sampling frequency. J Ecol 96(6): 1289-1296. doi:10.1111/j.1365-2745.2008.01436.x

Miller-Rushing AJ, Lloyd-Evans TL, Primack RB, Satzinger P (2008b) Bird migration times, climate change, and changing population sizes. Glob Chang Biol 14(9):1959-1972. doi:10.1111/j.13652486.2008.01619.x

Miller-Rushing AJ, Hoye TT, Inouye DW, Post E (2010) The effects of phenological mismatches on demography. Philos Trans R Soc B Biol Sci 365(1555):3177-3186. doi:10.1098/rstb.2010. 0148

Morellato LPC, Camargo MGG, D'Eça Neves FF, Luize BG, Mantovani A, Hudson IL (2010) The influence of sampling method, sample size, and frequency of observations on plant phenological patterns and interpretation in tropical forest trees. In: Hudson IL, Keatley MR (eds) Phenological research: methods for environmental and climate change analysis, 1st edn. Springer, Netherlands, pp 99-121. doi:10. 1007/978-90-481-3335-2 5

Ovaskainen O, Skorokhodova S, Yakovleva M, Sukhov A, Kutenkov A, Kutenkova N, Shcherbakov A, Meyke E, MdM D (2013) Community-level phenological response to climate change. Proc Natl Acad Sci. doi:10.1073/pnas.1305533110

Parmesan C (2006) Ecological and evolutionary responses to recent climate change. In: Annual Review of Ecology Evolution and Systematics, vol 37. Annual Review of Ecology Evolution and Systematics. pp 637-669. doi:10.1146/annurev.ecolsys.37.091305. 110100.

Parmesan C (2007) Influences of species, latitudes and methodologies on estimates of phenological response to global warming. Glob Chang Biol 13(9):1860-1872. doi:10.1111/j.1365-2486. 2007.01404.x

Peñuelas J, Filella I, Comas P (2002) Changed plant and animal life cycles from 1952 to 2000 in the Mediterranean region. Glob Chang Biol 8(6):531-544. doi:10.1046/j.1365-2486.2002.00489.x

Richardson AD, Bailey AS, Denny EG, Martin CW, O'Keefe J (2006) Phenology of a northern hardwood forest canopy. Glob Chang Biol 12(7):1174-1188. doi:10.1111/j.1365-2486.2006.01164.x

Richardson AD, Braswell BH, Hollinger DY, Jenkins JP, Ollinger SV (2009) Near-surface remote sensing of spatial and temporal variation in canopy phenology. Ecol Appl 19(6):1417-1428. doi:10.1890/082022.1

Root TL, Price JT, Hall KR, Schneider SH, Rosenzweig C, Pounds JA (2003) Fingerprints of global warming on wild animals and plants. Nature 421(6918):57-60. doi:10.1038/nature01333

Rosemartin AH, Crimmins TM, Enquist CAF, Gerst KL, Kellermann JL, Posthumus EE, Denny EG, Guertin P, Marsh L, Weltzin JF (2013) Organizing phenological data resources to inform natural resource conservation. Biol Conserv. doi:10.1016/j.biocon.2013.07.003, In Press

Schwartz MD, Ahas R, Aasa A (2006) Onset of spring starting earlier across the Northern Hemisphere. Glob Chang Biol 12(2):343-351. doi:10.1111/j.1365-2486.2005.01097.x

Schwartz MD, Ault TR, Betancourt JL (2012a) Spring onset variations and trends in the continental United States: past and regional assessment using temperature-based indices. Int J Climatol. doi:10.1002/ joc. 3625

Schwartz MD, Betancourt JL, Weltzin JF (2012b) From Caprio's lilacs to the USA National Phenology Network. Front Ecol Environ 10(6): 324-327

Schwartz M, Beaubien E, Crimmins T, Weltzin J (2013) North America. In: Schwartz MD (ed) Phenology: an integrative environmental science, 2nd edn. Springer, Netherlands

Sparks TH, Carey PD (1995) The responses of species to climate over 2 centuries - an analysis of the Marsham phenological record, 17361947. J Ecol 83(2):321-329. doi:10.2307/2261570 
Sparks TH, Bairlein F, Bojarinova JG, Hüppop O, Leihikoinen EA, Rainio K, Sokolov LV, Walker D (2005) Examining the total arrival distribution of migratory birds. Glob Chang Biol 11:22-30

Thackeray SJ, Sparks TH, Frederiksen M, Burthe S, Bacon PJ, Bell JR, Botham MS, Brereton TM, Bright PW, Carvalho L, Clutton-Brock T, Dawson A, Edwards M, Elliott JM, Harrington R, Johns D, Jones ID, Jones JT, Leech DI, Roy DB, Scott WA, Smith M, Smithers RJ, Winfield IJ, Wanless S (2010) Trophic level asynchrony in rates of phenological change for marine, freshwater and terrestrial environments. Glob Chang Biol 16(12):3304-3313. doi:10.1111/j.13652486.2010.02165.x

Thomson JD (1980) Skewed flowering distributions and pollinator attraction. Ecology 61(3):572-579

Tierney G, Mitchell B, Miller-Rushing A, Katz J, Denny E, Brauer C, Donovan T, Richardson AD, Toomey M, Kozlowski A, Weltzin J, Gerst K, Sharron E, Sonnentag O, Dieffenbach F (2013) Phenology monitoring protocol: Northeast Temperate Network. Natural Resource Report. NPS/NETN/NRR-2013/681. Fort Collins, $\mathrm{CO}$

Tooke F, Battey NH (2010) Temperate flowering phenology. J Exp Bot 61(11):2853-2862. doi:10.1093/jxb/erq165

van Asch M, Visser ME (2007) Phenology of forest caterpillars and their host trees: The importance of synchrony. In: Annual Review of Entomology, vol 52. Annual Review of Entomology. pp 37-55. doi:10.1146/annurev.ento.52.110405.091418

Van Vliet AJH, Overeem A, De Groot RS, Jacobs AFG, Spieksma FTM (2002) The influence of temperature and climate change on the timing of pollen release in the Netherlands. Int J Climatol 22(14): 1757-1767. doi:10.1002/joc. 820
Vitasse Y, Porte AJ, Kremer A, Michalet R, Delzon S (2009) Responses of canopy duration to temperature changes in four temperate tree species: relative contributions of spring and autumn leaf phenology. Oecologia 161(1):187-198. doi:10.1007/s00442-009-1363-4

Westerling AL, Hidalgo HG, Cayan DR, Swetnam TW (2006) Warming and earlier spring increase western US forest wildfire activity. Science 313(5789):940-943. doi:10.1126/science. 1128834

Willis CG, Ruhfel B, Primack RB, Miller-Rushing AJ, Davis CC (2008) Phylogenetic patterns of species loss in Thoreau's woods are driven by climate change. Proc Natl Acad Sci U S A 105(44):17029 17033. doi:10.1073/pnas.0806446105

Wolfe DW, Schwartz MD, Lakso AN, Otsuki Y, Pool RM, Shaulis NJ (2005) Climate change and shifts in spring phenology of three horticultural woody perennials in northeastern USA. Int $\mathrm{J}$ Biometeorol 49(5):303-309. doi:10.1007/s00484-004-0248-9

Wolkovich EM, Cook BI, Allen JM, Crimmins TM, Betancourt JL, Travers SE, Pau S, Regetz J, Davies TJ, Kraft NJB, Ault TR, Bolmgren K, Mazer SJ, McCabe GJ, McGill BJ, Parmesan C, Salamin N, Schwartz MD, Cleland EE (2012) Warming experiments underpredict plant phenological responses to climate change. Nature 485(7399):494-497. doi:10.1038/nature11014

Ziska L, Knowlton K, Rogers C, Dalan D, Tierney N, Elder MA, Filley W, Shropshire J, Ford LB, Hedberg C, Fleetwood P, Hovanky KT, Kavanaugh T, Fulford G, Vrtis RF, Patz JA, Portnoy J, Coates F, Bielory L, Frenz D (2011) Recent warming by latitude associated with increased length of ragweed pollen season in central North America. Proc Natl Acad Sci U S A 108(10):4248-4251. doi:10. 1073/pnas. 1014107108 